\title{
Risk Factors for Collisions and Near-Miss Incidents Caused by Drowsy Bus Drivers
}

\author{
Genta Miyama ${ }^{1, *(\mathbb{D})}$, Masakatsu Fukumoto ${ }^{2}$, Ritsuko Kamegaya ${ }^{3}$ and Masahito Hitosugi ${ }^{1}$ \\ 1 Department of Legal Medicine, Shiga University of Medical Science, Shiga 520-2192, Japan; \\ hitosugi@belle.shiga-med.ac.jp \\ 2 i.OH Laboratory Co., Ltd., Tokyo 153-0063, Japan; ae86fm@hotmail.co.jp \\ 3 Health Service Planning, Tokyo 160-0022, Japan; ritsuko.kamegaya@healthservice-p.net \\ * Correspondence: racoondy@gmail.com; Tel.: +81-77-548-2200
}

Received: 30 May 2020; Accepted: 16 June 2020; Published: 18 June 2020

\begin{abstract}
Serious accidents have been caused by drowsy bus drivers and have necessitated an examination of the risk factors involved. A questionnaire survey among employees of a bus company was conducted in Ibaraki Prefecture, Japan in September 2014. Respondents were asked to report details of their work and life over the preceding month. The 301 valid responses by bus drivers (295 men and 6 women) with a mean age of 51.6 years (range: 24-73 years) were used for analysis. Univariable logistic regression showed that factors affecting the incidence of collisions and near-miss incidents by drowsy drivers were continued driving when feeling sick, reporting a physical condition, number of sleep hours, time spent with family, working hours, and nutritional balance. According to a multiple regression analysis, continued driving when feeling sick (odds ratio: $3.421,95 \%$ confidence interval: 1.618-7.231) was the only significant risk for the event. Managers should encourage drivers to voluntarily report poor health and should provide opportunities to stop driving if drivers experience physical discomfort or sleepiness. To improve road safety, educational measures are required for both drivers and managers to prevent driving under poor health conditions, although the decision to stop driving depends on drivers' subjective judgment.
\end{abstract}

Keywords: drowsy driving; risk factors; bus drivers; safety education; risk management

\section{Introduction}

As part of regulatory reform in public transportation, Japan's Ministry of Land, Infrastructure, Transport, and Tourism (MLIT) deregulated the chartered-bus, route-bus, and highway-bus business in 2000, hoping to revitalize the industry. According to MLIT statistics, deregulation was immediately followed by a near doubling of the number of new entrants, including those from other sectors, such as taxi operators, into the chartered-bus business [1]. Additionally, online reservations increased with the development of information-delivering means on buses; the opportunities for brand recognition by potential users have resulted in the growth of the chartered-bus business [2]. Efforts to improve service and optimize efficiency have contributed to the revitalization of the industry [1].

However, deregulation has created excessive competition among operators, which has led to a worsening working environment for bus drivers. Major crashes, including a tour-bus crash with seven fatalities on an expressway in Gunma Prefecture in 2012 [3] and a ski-bus crash with 15 fatalities including two bus drivers in Nagano Prefecture in 2016 [4], have raised public awareness regarding the dangers of drowsiness in bus drivers. Subsequently, both the public and private sectors have undertaken various measures to improve drivers' working conditions. For example, in 2016, MLIT mandated that bus operators record and store video footage of accidents and near-miss incidents using a drive recorder [5]; this footage is used for driver education and to determine the causes of 
these incidents during the ensuing investigations. In 2018, MLIT revised its safety regulations on commercial passenger-transportation businesses to add a provision that requires drivers to report lack of sleep in a roll call prior to driving [6]. According to a systematic review, drowsiness and fatigue significantly impair driving performance and expose drivers to increased risk [7]. In the United States, drowsy drivers account for an estimated $16.5 \%$ of fatal crashes and $13.1 \%$ of crashes leading to hospitalizations [8]. Thus, the prevention of driving while drowsy is an urgent public health issue. However, the risk factors leading to drowsiness-related driving accidents remain to be comprehensively identified.

Various potential technological solutions for reducing the load on bus drivers have been developed in recent years. One potential aid is the introduction of automated vehicles. In Japan, Tokyo Electric Power Company Holdings (TEPCO) introduced a self-driving bus in 2018 as a means of transporting field workers at the Fukushima No. 1 Nuclear Power Plant [9]. However, this bus runs only on preprogrammed routes. Regarding the introduction of self-driving vehicles on public roads, MITI plans to revise relevant laws for setting up priority lanes exclusively for self-driving vehicles on some sections of expressways [10]. On highways, offering point-to-point services would be a solution in which autonomous vehicles follow the routes instructed by the system's control center; the control center assigns transportation requests to the appropriate self-driving vehicles [11]. The impact of advancements in mobility with the introduction of autonomous vehicles would be visible on highways connecting urban areas; however, this system would not be beneficial in rural areas [12] in which irregular roads and circumstances that may confound the sensing techniques of automated vehicles are prevalent. Furthermore, when a takeover is required, the drivers must drive the vehicle manually.

There are still many problems to be solved in the introduction of self-driving vehicles. Azmat et al. [12] noted the threat of cybercrime. Communication between devices is achieved with the help of sensors, tags, and radio frequency identification; these endanger data authentication and integrity as this kind of wireless communication remains vulnerable to cyberattacks. An online survey suggested that another hurdle in introducing self-driving vehicles is skepticism about the technology among consumers. Despite the high number of vehicle collisions, the subjective feeling of safety in conventional vehicles is very high among the general public. This distorted perception complicates the introduction of autonomous vehicles [13]. Therefore, despite developments in automated vehicle technology and systems, human drivers must still be responsible for safe vehicle driving for the next several years.

Another potential solution is the adoption of drowsiness prediction systems using Internet-based technologies. Recently, machine learning was applied to predict drowsiness and to improve drowsiness prediction using facial recognition technology, eye-blink recognition technology, and $\mathrm{CO}_{2}$-sensing technology [14]. Further development of technologies for objectively measuring the level of drowsiness of the driver and for informing them to stop driving and to rest at appropriate times can be expected in the near future. This technology may also contribute to reducing vehicle collisions, and some bus companies have already introduced such systems. However, these solutions involve a substantial cost for bus companies. Furthermore, some recently developed systems cannot be used for all roads. Therefore, the current study focused on steps that bus drivers and their companies can apply immediately rather than exploring potential future technological solutions.

For taxi drivers, the influence of several health status factors on the incidence of vehicle collisions has been investigated, including fatigue, drowsiness, and disease onset. One previous study revealed that fatigue management strategies to identify individual factors, business-related characteristics, and work environment factors are important components of road safety [15]. A study of taxi drivers indicated that an insufficient number of days off work and difficulty reporting poor health conditions were influential risk factors in collisions and near-miss incidents [16]. However, no previous studies have elucidated drowsiness-related factors that influence incidents caused by bus drivers. Identifying these risk factors would provide a valuable first step for formulating policies to reduce collisions or near-miss incidents by bus drivers. In the present investigation, a questionnaire-based survey among 
employees of a bus company was conducted in Ibaraki Prefecture, Japan to identify the risk factors that lead to drowsy driving.

To address the objectives of this study, measures for preventing vehicle collisions caused by drowsiness in bus drivers were investigated. Several recommendations are made for both bus drivers and bus company managers.

\section{Materials and Methods}

\subsection{Subjects}

The present study was designed to reveal the risk factors involved in drowsy driving and to identify the problems currently faced by bus drivers and their companies. To answer these research questions, a questionnaire survey was conducted. The questionnaire targeted all 609 employees-regular drivers, occasional drivers, and administrative staff-of a bus company operating chartered/highway/route buses in Ibaraki Prefecture, which is adjacent to metropolitan Tokyo. The survey was conducted in September 2014 using a non-anonymous questionnaire with a closed-ended format. The reason for the non-anonymity of the questionnaire was that the results were used for medical intervention by occupational physicians to improve the health status of employees. Respondents were asked to report details of their work and life in the month preceding the survey and to return the completed survey to their physician. The self-administered questionnaire with an explanation of the research objective included a statement assuring the participants of the survey's anonymity. The protocol of the investigation and research was approved by the ethics committee of Dokkyo Medical University (Univ. 24002).

\subsection{Questionnaire Items}

With reference to a safety education manual published by MLIT for passenger transport operators, such as bus, truck, and taxi companies [17], it was assumed that risk factors of drowsy driving would include drivers' worsening working conditions, reduced sleep quantity and quality, and physical or mental stress. Therefore, the questions were designed using that assumption. The questionnaire covered 200 items grouped under eight categories, as follows.

1. General characteristics: age, sex, body mass index, marital status, years of driving-work experience, full-time/part-time employment, and type of bus driving (route/express/chartered)

2. Lifestyle: exercise, smoking, alcohol consumption, nutritional balance, medical conditions, and noticeable symptoms related to a physical disorder

3. Driving conditions during the preceding month: physical conditions during driving

4. Sleep during the preceding month: sleeping time, disorders such as sleep apnea (breathing stops and restarts during sleep)

5. Incidents/accidents related to drowsy driving during the preceding month: collisions or near-miss incidents and the causes of major accidents, if any

6. Stress during the preceding month, from both life and work

7. Fatigue during the preceding month: mental and physical factors causing fatigue

8. Requests for improvement of working conditions: 15 questions concerning worsening working conditions and their effects on physical or mental stress, reduced sleep quantity and quality, or lack of time spent with family.

\subsection{Analysis Method}

In analyzing the questionnaire data, the focus was only on drivers' responses. To identify the most relevant risk factors for drowsy driving, both unilateral and multilateral regression analyses were conducted. Drivers were classified into two groups: an event group, who had experienced collisions or near-miss incidents because of drowsy driving, and a nonevent group, who had experienced no 
such incidents. In the current study, a logistic regression model was used to analyze risk factors. This model uses data to predict the likelihood of occurrence of a particular event and is useful for identifying risk factors. To identify the risk factors of drowsy driving, univariable and multivariable logistic regressions were conducted using IBM SPSS Statistics ver. 23 (IBM Corp., Armonk, NY, USA). $p<0.05$ was considered statistically significant.

\section{Results}

\subsection{Subject Characteristics}

Valid responses were obtained from 519 of the 609 employees $(85.2 \%)$; the number of drivers in that cohort was 301. Most of the drivers (295 of 301) were male. Mean age was 51.6 years (range: 24-73 years). Mean body mass index of the drivers was $24.3 \mathrm{~kg} / \mathrm{m}^{2}$, and $73.8 \%$ were married. Mean number of years of driving buses was 20.2 (range: $0.1-54$ years), and $78.2 \%$ of the drivers had more than 20 years of experience (Figure 1).

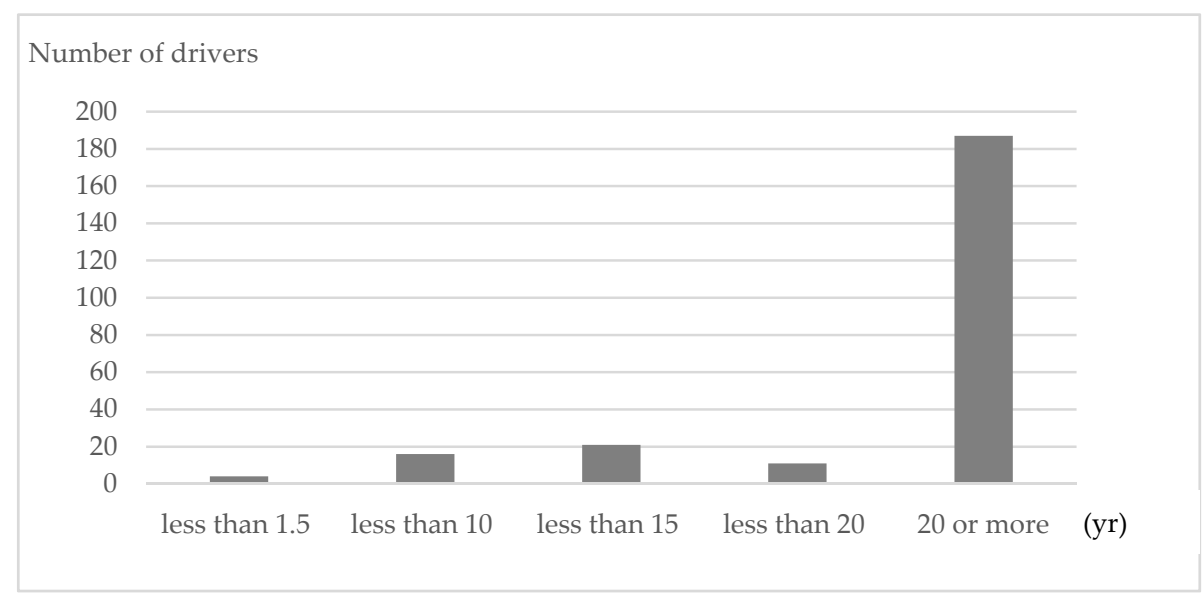

Figure 1. Driving experience of drivers in the survey.

Table 1 lists the drivers' travel distance per month, stratified by the type of bus driving. Half the respondents (50.9\%) were full-time drivers, and $41.5 \%$ were part-time drivers.

Table 1. Average travel distance $(\mathrm{km} / \mathrm{month})$ by the type of bus driving.

\begin{tabular}{cccc}
\hline \multirow{2}{*}{ Type of Bus Driving } & Number of Drivers & \multicolumn{2}{c}{ Mean Mileage (SD) } \\
\cline { 3 - 4 } & $\mathrm{N}=301$ & & \\
& & & \\
Rousy Season & Off-Season \\
Highway & 186 & $5735(1756)$ & $5433(890)$ \\
Chartered & 18 & $5039(2696)$ & $3325(1109)$ \\
Route and Highway & 14 & $5963(2093)$ & $5862(1877)$ \\
Route and chartered & 24 & $5625(2615)$ & $2643(1749)$ \\
All & 10 & $7555(3253)$ & $5409(2773)$ \\
Unknown & 14 & $2181(1520)$ & $2083(1157)$ \\
\hline
\end{tabular}

\subsection{Lifestyle}

More than half of respondents (54.2\%) reported that they exercised regularly. Approximately one-third (34\%) smoked, with an average of 17.4 cigarettes per day. More than half of drivers $(56.8 \%)$ reported consuming alcohol, at an average of 4.4 times per week. The average amount of alcohol consumed was 1.5 go (about $270 \mathrm{~mL}$ ), and the interval between ending alcohol consumption and 
beginning driving work was 9.8 h. Some drivers (14.6\%) reported skipping breakfast, while $42.5 \%$ ate three meals regularly each day.

Figure 2 shows the prevalence of diseases and medical conditions reported by drivers (multiple answers allowed). In all, 167 drivers (55.5\%) reported at least one current condition, 108 of them $(64.7 \%)$ attended a hospital at the time of the survey, and almost all of them told their physicians about their driving duties. Approximately $41 \%$ of drivers reported taking medication, and three reported that the medication affected their driving. The physical symptoms most reported by drivers were back pain $(51 \%)$ and stiff shoulders (53\%).

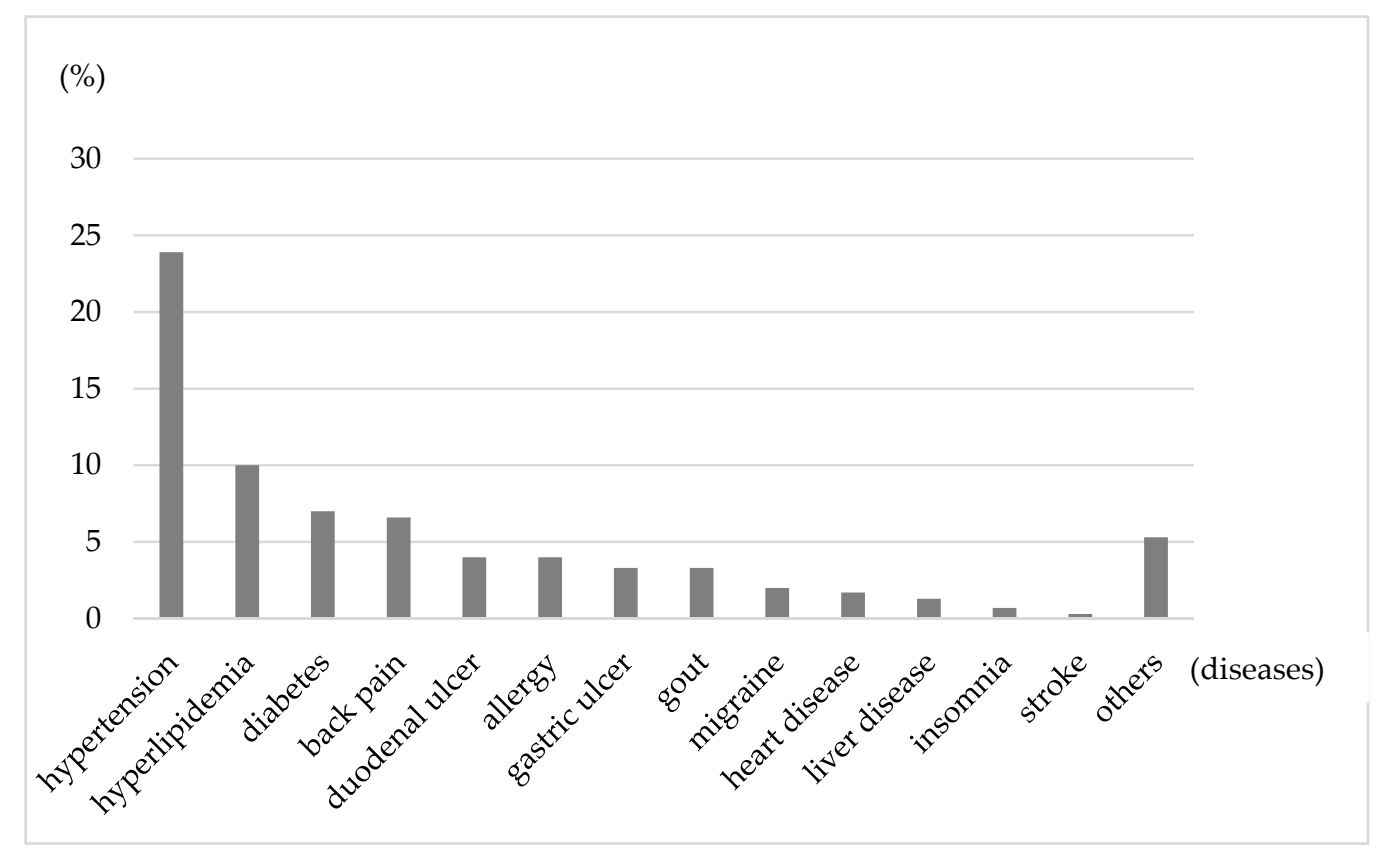

Figure 2. Prevalence of diagnosed diseases and medical conditions reported by bus drivers.

\subsection{Driving Conditions during Preceding Month}

Of 278 drivers, 37 (13.3\%) had experienced poor physical conditions one or more times during driving. About 37\% of drivers reported that they were reluctant to alert the company when feeling sick. When these drivers were asked what they did when experiencing poor physical conditions, some responded that they stopped driving (27.4\%), continued driving (21.6\%), or continued driving after using the bathroom $(10.8 \%)$.

\subsection{Sleep during Preceding Month}

The sleep guidelines for health promotion by MLIT note that $7 \mathrm{~h}$ of sleep result in the lowest risk of lifestyle-related illness or death [17]. One study suggested that driving after sleeping $6 \mathrm{~h}$ or less and multiple driving sessions were significantly associated with both rear-end collisions and single-car accidents [18]. The drivers reported sleeping an average of $6.4 \mathrm{~h}$, but $26.0 \%$ of the drivers reported sleeping less than $6 \mathrm{~h}$ and $23.8 \%$ of all drivers reported experiencing symptoms of sleep apnea. Additionally, 25.3\% of drivers reported experiencing sleepiness sometimes or frequently.

\subsection{Incidents or Accidents Related to Drowsy Driving during Preceding Month}

Near-miss incidents in the month preceding the survey were reported by 134 respondents (44.5\%), and 35 drivers (11.7\%) experienced collisions once or twice. The frequency of near-miss incidents was reported as "sometimes" by 34 drivers (11.4\%) and "frequently" by two drivers (0.7\%). When asked about the main causes of major accidents, 192 drivers cited heavy traffic $(64.1 \%)$, poor working/break 
conditions (63.0\%), lack of safety education (50.0\%), irresponsible behavior by drivers (32.8\%), and poor driving skills of drivers $(31.8 \%)$.

\subsection{Stress during Preceding Month from Both Life and Work}

Two-thirds (68.5\%) of the drivers reported that their lives were "always busy" or "often busy", and $63.4 \%$ reported feeling a lack of time. Approximately $60 \%$ felt that they were busy because they had too much work, and $67.4 \%$ stated that consulting their supervisors regarding their workload would be difficult.

\subsection{Fatigue during Preceding Month: Mental and Physical Factors Causing Fatigue}

Nearly half of the respondents cited mental factors (48.5\%) such as "worries", "tension", "lack of concentration", and "lack of satisfaction" or physical factors (43.2\%) such as "irregular working conditions", "great burden associated with extra work", and "late-night shifts" as the causes of their fatigue. One-third of the drivers (33.9\%) complained that the amenities and facilities for rest breaks were not satisfactory.

\subsection{Requests for Improved Working Conditions}

The respondents were given a list of 15 items related to working conditions and were permitted to select as many as they felt applied to their situation. The factors cited most often as adversely affecting the drivers' working conditions were as follows: low salary $(82.6 \%)$, difficulty in taking days off $(71.7 \%)$, irregular working hours $(71.6 \%)$, irregular meal times $(70.2 \%)$, long working hours $(69.4 \%)$, not enough social time with friends $(63.1 \%)$, not enough time spent with family $(56.4 \%)$, fatigue from work $(53.1 \%)$, poor rest facilities $(51.4 \%)$, inadequate bathroom (toilet) time $(48 \%)$, not enough time for sleep $(47.8 \%)$, poor ventilation $(29.9 \%)$, and inadequate breaks $(28.5 \%)$.

\subsection{Analysis of Risk Factors}

Univariable logistic regression was used to analyze the risk factors of drowsy driving between the event group and the nonevent group. Table 2 shows that continued driving when feeling sick, reporting a physical condition, inadequate sleep, inadequate time spent with family, long working hours, and nutritional balance were factors that affected the incidence of collisions and near misses.

Next, multiple logistic regression was conducted using a collision or near miss as a dependent variable. Independent variables were as follows: age, alcohol consumption, nutritional balance, poor physical conditions during driving, continued driving when feeling sick, reporting a physical condition, feelings of stress, irregular working hours, number of sleep hours, and time spent with family. These factors were selected if their differential values between the event (collision or near miss) and nonevent groups in univariable analysis were $p<0.1$. Continued driving when feeling sick was found to be a significant risk factor in collisions or near misses (odds ratio (OR): $3.421,95 \%$ confidence interval: 1.618-7.231; Table 3).

In the regression model, the coefficient of determination summarizes the proportion of variance in the dependent variable associated with the independent variables. In the present study, the pseudo-determination coefficient (Nagelkerke R-squared value) was 0.142. Additionally, the Wald test results revealed a significant probability of 0.0009 , indicating that the model was statistically appropriate. 
Table 2. Univariable logistic regression analysis of risk factors for collisions and near misses.

\begin{tabular}{|c|c|c|c|c|c|}
\hline & Event Group & Nonevent Group & Odds Ratio & $95 \% \mathrm{CI}$ & $p$-Value \\
\hline & $\mathrm{N}=170$ & $\mathrm{~N}=131$ & & & \\
\hline \multicolumn{6}{|l|}{ Gender } \\
\hline Male & 167 & 128 & Reference & & \\
\hline Female & 3 & 3 & 0.766 & $0.151-3.896$ & 0.748 \\
\hline \multicolumn{6}{|c|}{ Age (elderly person) } \\
\hline Less than $65 \mathrm{yr}$ & 151 & 107 & Reference & & \\
\hline $65 \mathrm{yr}$ or older & 19 & 24 & 0.561 & $0.292-1.079$ & 0.083 \\
\hline \multicolumn{6}{|l|}{ Marital status } \\
\hline Married & 124 & 98 & Reference & & \\
\hline \multicolumn{6}{|l|}{ BMI } \\
\hline Normal & 103 & 74 & Reference & & \\
\hline Low & 5 & 3 & 1.197 & $0.275-5.211$ & 0.622 \\
\hline High & 62 & 54 & 0.825 & $0.513-1.325$ & 0.425 \\
\hline \multicolumn{6}{|l|}{ Exercise habits } \\
\hline No & 81 & 57 & Reference & & \\
\hline Yes & 89 & 74 & 0.846 & $0.534-1.342$ & 0.477 \\
\hline \multicolumn{6}{|l|}{ Smoking habits } \\
\hline No & 110 & 87 & Reference & & \\
\hline Yes & 60 & 44 & 1.079 & $0.666-1.748$ & 0.758 \\
\hline \multicolumn{6}{|l|}{ Drinking habits } \\
\hline No & 66 & 64 & Reference & & \\
\hline Yes & 104 & 67 & 1.505 & $0.947-2.393$ & 0.084 \\
\hline \multicolumn{6}{|l|}{ Eating breakfast } \\
\hline No & 25 & 21 & Reference & & \\
\hline Yes & 145 & 110 & 1.107 & $0.587-2.088$ & 0.752 \\
\hline \multicolumn{6}{|l|}{ Eating habits } \\
\hline Irregular & 106 & 66 & Reference & & \\
\hline Regular & 64 & 65 & 0.613 & $0.385-0.976$ & 0.039 \\
\hline \multicolumn{6}{|c|}{ Nutritional balance } \\
\hline Poor & 100 & 58 & Reference & & \\
\hline Good & 70 & 73 & 0.658 & $0.415-1.043$ & 0.075 \\
\hline \multicolumn{6}{|c|}{$\begin{array}{l}\text { Having current or past } \\
\text { illnesses }\end{array}$} \\
\hline No & 91 & 55 & Reference & & \\
\hline Yes & 79 & 76 & 0.834 & $0.525-1.323$ & 0.439 \\
\hline \multicolumn{6}{|c|}{$\begin{array}{l}\text { Feeling a poor physical } \\
\text { condition while driving }\end{array}$} \\
\hline No & 142 & 119 & Reference & & \\
\hline Yes & 28 & 12 & 1.955 & $0.949-4.029$ & 0.069 \\
\hline \multicolumn{6}{|c|}{$\begin{array}{l}\text { Continued driving when } \\
\text { feeling sick }\end{array}$} \\
\hline No & 106 & 113 & Reference & & \\
\hline Yes & 64 & 18 & 3.790 & $2.102-6.835$ & 0.000 \\
\hline \multicolumn{6}{|c|}{$\begin{array}{l}\text { Reporting a physical } \\
\text { condition }\end{array}$} \\
\hline Easy & 100 & 98 & Reference & & \\
\hline Difficult & 70 & 33 & 2.079 & $1.259-3.433$ & 0.004 \\
\hline \multicolumn{6}{|l|}{ Feeling stress } \\
\hline No & 119 & 107 & Reference & & \\
\hline Yes & 51 & 24 & 1.911 & $1.098-3.325$ & 0.022 \\
\hline $\begin{array}{l}\text { Feeling free to talk } \\
\text { superiors }\end{array}$ & & & & & \\
\hline No & 117 & 79 & Reference & & \\
\hline Yes & 53 & 52 & 0.688 & $0.426-1.112$ & 0.127 \\
\hline $\begin{array}{l}\text { Feeling free to talk } \\
\text { colleagues }\end{array}$ & & & & & \\
\hline No & 118 & 90 & Reference & & \\
\hline Yes & 52 & 41 & 0.967 & $0.589-1.588$ & 0.895 \\
\hline Irregular working $\mathrm{h}$ & & & & & \\
\hline Few times & 92 & 87 & Reference & & \\
\hline Many times & 78 & 44 & 1.676 & $1.043-2.694$ & 0.033 \\
\hline Number of sleep ho & & & & & \\
\hline Enough & 76 & 85 & Reference & & \\
\hline Not enough & 94 & 46 & 2.232 & $1.393-3.577$ & 0.001 \\
\hline Time spent with far & & & & & \\
\hline Enough & 63 & 74 & Reference & & \\
\hline Not enough & 107 & 57 & 2.205 & $1.381-3.520$ & 0.001 \\
\hline
\end{tabular}

BMI, body mass index; CI, confidence interval. 
Table 3. Multivariable logistic regression analysis of risk factors for collisions and near-miss incidents related to drowsy driving $(\mathrm{N}=301)$.

\begin{tabular}{|c|c|c|c|}
\hline & Odds Ratio & $95 \% \mathrm{CI}$ & $p$-Value \\
\hline \multicolumn{4}{|c|}{ Age (elderly person) } \\
\hline Less than $65 \mathrm{yr}$ & Reference & & \\
\hline 65 yr or older & 0.920 & $0.431-1.963$ & 0.829 \\
\hline \multicolumn{4}{|l|}{ Drinking habits } \\
\hline No & Reference & & \\
\hline Yes & 1.575 & $0.963-2.576$ & 0.070 \\
\hline \multicolumn{4}{|l|}{ Eating habits } \\
\hline Irregular & Reference & & \\
\hline Regular & 0.981 & $0.513-1.874$ & 0.953 \\
\hline \multicolumn{4}{|l|}{ Nutritional balance } \\
\hline Poor & Reference & & \\
\hline Good & 0.879 & $0.473-1.632$ & 0.681 \\
\hline \multicolumn{4}{|c|}{$\begin{array}{c}\text { Feeling a poor physical condition } \\
\text { during driving }\end{array}$} \\
\hline No & Reference & & \\
\hline Yes & 0.730 & $0.290-1.843$ & 0.505 \\
\hline \multicolumn{4}{|c|}{$\begin{array}{l}\text { Continued driving when feeling } \\
\text { sick }\end{array}$} \\
\hline No & Reference & & \\
\hline Yes & 3.421 & $1.618-7.231$ & 0.001 \\
\hline \multicolumn{4}{|c|}{ Reporting a physical condition } \\
\hline Easy & Reference & & \\
\hline Difficult & 1.002 & $0.556-1.805$ & 0.995 \\
\hline \multicolumn{4}{|l|}{ Feeling stress } \\
\hline No & Reference & & \\
\hline Yes & 1.175 & $0.619-2.232$ & 0.621 \\
\hline \multicolumn{4}{|c|}{ Irregular working hours } \\
\hline Few times & Reference & & \\
\hline Many times & 1.017 & $0.579-1.786$ & 0.953 \\
\hline \multicolumn{4}{|c|}{ Number of sleep hours } \\
\hline Enough & Reference & & \\
\hline Not enough & 1.299 & $0.690-2.446$ & 0.416 \\
\hline \multicolumn{4}{|c|}{ Time spent with family } \\
\hline Enough & Reference & & \\
\hline Not enough & 1.465 & $0.775-2.769$ & 0.238 \\
\hline
\end{tabular}

CI, confidence interval.

\section{Discussion}

To combat the increased number of accidents caused by driver health, MLIT issued a revised health-care manual for commercial drivers in 2016, citing in particular the need for ensuring adequate

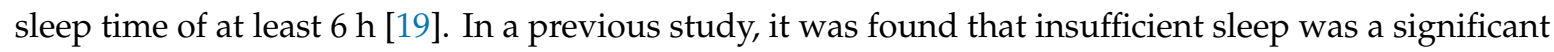
factor in incidents or accidents related to driving while drowsy [16]. Other relevant factors identified were overwork, chronic lack of rest, and drowsiness caused by consuming alcohol, taking medications, or sleep apnea [20].

Previous studies have reported that bus drivers experience drowsy driving, sleep problems, and low sleep quality [21-23]. In one study, approximately one in four bus drivers in Peru reported experiencing drowsy driving, and this factor increased the risk of collisions and near-miss incidents [24]. In another study, to determine the influence of sleep quality on drowsy driving, sleep quality and associated factors were investigated among Thai intercity bus drivers [25]. The results revealed that working night shifts (odds ratio of 20.6), rotating day and night shifts (OR of 17.0), alcohol consumption (OR of 2.7), being married (OR of 3.1), and not exercising (OR of 2.3) were related to poor sleep quality [25]. The authors of the study suggested that both the bus company and the individual should 
take steps to maintain healthy lifestyles and to improve working conditions [23]. On the basis of these previous studies, the present study examined the factors involved in drowsy driving that can cause collisions or near-miss events among bus drivers.

A previous study in commercial drivers in Japan suggested that bus drivers had a lower threshold for reporting sudden illness than taxi or truck drivers because of their belief in the importance of passenger safety [26]; however, it also found a tendency in the commercial drivers to continue driving under poor physical conditions. The current results revealed that continuing driving when feeling sick was a major risk factor for collisions and near-miss incidents. Therefore, increased education for both drivers and company managers is required. In a previous study, an analysis using a driving simulator suggested that an education program to increase knowledge of the impact of sleepiness on driving could reduce the risk of drowsy driving and associated road trauma in young drivers [27]. Bus companies should advise their drivers to report health conditions to supervisors and to refrain from driving when feeling unwell: the cooperation of the companies is essential. Managers should encourage drivers to voluntarily report poor health and should provide opportunities to stop driving when drivers feel physical discomfort or sleepiness. Overall, a working environment that encourages drivers to voluntarily and easily report health problems should be fostered.

Currently, annual health checkups are mandated for commercial drivers such as bus drivers, but drivers may or may not disclose personal information to employers. To prevent collisions, an environment that does not penalize drivers for reporting their physical and mental conditions should be fostered and more comfortable, well-equipped rest facilities should be provided.

Mental stress resulting from dissatisfaction with inadequate family time was also a significant factor in the incidence of collisions and near misses. Increased competition in the chartered-bus industry has forced drivers to extend their working hours. A report by Japan's Ministry of Internal Affairs and Communications noted that the average annual total working hours per bus driver was 1.3 times that of all industrial workers [28]. A recent study by our group in a cohort of taxi drivers found that insufficient vacation time was cited as the most influential risk factor for collision-related events, which indicated accumulated fatigue [16]. This reinforces the importance of cooperation by company managers in improving drivers' work/life satisfaction and balance.

\section{Conclusions}

To identify risk factors for collisions and near-miss incidents caused by drowsiness among bus drivers, a questionnaire survey of employees of a bus company in Japan was conducted. Using univariable logistic regression and multiple regression analyses, it was shown that continuing to drive when feeling sick was a major risk factor for such incidents.

The current study involved several limitations that should be considered. First, "drowsiness" and "near misses" were determined subjectively; therefore, the near misses based on drowsy driving may be underestimated. In a future study, near misses or drowsy driving should be determined objectively using driving recorders and onboard cameras to photograph drivers and to confirm the present results. Second, recent levels of fatigue and psychological conditions (within 1 month of the survey) were investigated. These factors should also be evaluated immediately after accidents or near-miss incidents. Third, the employees of only one company in one prefecture were surveyed; a cross-sectional survey of multiple companies and their regional characteristics will be necessary in the future. Fourth, drivers were surveyed in a non-anonymous manner, which may have biased the respondents toward underreporting near misses, physical conditions, and personal habits and problems. Fifth, this survey was conducted in September, immediately following a busy travel season, and many drivers complained that their physical and psychological loads were too high. Conducting a similar survey during the off-season may yield different findings.

Unfortunately, drivers were reluctant to report health conditions to their supervisors. Therefore, it is important for drivers and managers to have a better understanding of the risk factors that lead to 
sleep deprivation and subsequent accidents. Improving the work environment to maintain the mental and physical health of drivers could increase road safety.

Author Contributions: G.M. conceptualized the study, analyzed data and drafting the manuscript; M.F. performed the survey and collected the data; R.K. performed the survey, collected data and edited the draft; M.H. conceptualized and supervised the study, edited and finalized the manuscript. All authors have read and agreed to the published version of the manuscript.

Funding: This research received no external funding.

Conflicts of Interest: The authors declare no conflict of interest.

\section{References}

1. Japan Ministry of Land, Infrastructure, Transport and Tourism. White Paper on Land, Infrastructure. 2013. Available online: https://www.mlit.go.jp/hakusyo/mlit/h14/H14/html/E2013120.html (accessed on 4 December 2019).

2. Takahashi, Y. Ten years after the bus deregulation in Japan: Toward an evaluation of the abolition of demand-supply balancing. Shoukei Gakusou 2011, 57, 875-895.

3. The Japan Times, Bus Crash in Gunma Leaves Seven Dead, 39 Injured. 2012. Available online: https://www.japantimes.co.jp/news/2012/04/30/national/bus-crash-in-gunma-leaves-seven-dead-39injured/\#.Xrs_SWgzbD4 (accessed on 6 February 2020).

4. The Japan Times, Overnight Bus Crashes in Karuizawa, Killing 14. 2016. Available online: https://www.japantimes.co.jp/news/2016/01/15/national/night-ski-bus-flips-karuizawa-three-killed11-critical-condition/\#.XrtCAWgzbD4 (accessed on 6 February 2020).

5. Japan Ministry of Land, Infrastructure, Transport and Tourism. Report on the Current Situation of Chartered-Bus Business. 2016. Available online: https://www.mlit.go.jp/common/00137244.pdf (accessed on 6 December 2019).

6. Japan Ministry of Land, Infrastructure, Transport and Tourism. Strengthening Measures to Prevent Accidents Caused by Lack of Sleep. 2018. Available online: http://www.mlit.go.jp/report/press/jidosha02_hh_000341. html (accessed on 14 December 2019).

7. Soares, S.; Ferreira, S.; Couto, A. Driving simulator experiments to study drowsiness: A systematic review. Traffic Inj. Prev. 2020, 21, 875-895. [CrossRef] [PubMed]

8. Tefft, B.C. Prevalence of motor vehicle crashes involving drowsy drivers, United States, 1999-2008. Accid. Anal. Prev. 2012, 45, 180-186. [CrossRef] [PubMed]

9. The Asahi Shimbun Degital, Self-Driving EV Buses Start Operating at Fukushima No. 1 Nuclear Power Plant. 2018. Available online: https://www.asahi.com/articles/ASL4L5CPVL4LUGTB00Z.html (accessed on 8 May 2020).

10. The Japan News, Legal Revisions Eyed to Set Up Priority Lanes for Automated Driving. 2019. Available online: https://elevenmyanmar.com/news/legal-revisions-eyed-to-set-up-priority-lanes-for-automateddriving (accessed on 8 May 2020).

11. Lam, A.Y.; Leung, Y.W.; Chu, X. Autonomous vehicle public transportation system. In Proceedings of the 2014 International Conference on Connected Vehicles and Expo (ICCVE), Vienna, Austria, 3-7 November 2014; pp. 571-576.

12. Azmat, M.; Kummer, S.; Moura, L.T.; Gennaro, F.D.; Moser, R. Future Outlook of Highway Operations with Implementation of Innovative Technologies Like AV, CV, IoT and Big Data. Logistics 2019, 3, 15. [CrossRef]

13. Wintersberger, S.; Azmat, M.; Kummer, S. Are We Ready to Ride Autonomous Vehicles? A Pilot Study on Austrian Consumers' Perspective. Logistics 2019, 3, 20. [CrossRef]

14. Jang, S.W.; Ahn, B. Implementation of Detection System for Drowsy Driving Prevention Using Image Recognition and IoT. Sustainability 2020, 12, 3037. [CrossRef]

15. Menéndez, C.; Socias-Morales, C.; Konda, S.; Ridenour, M. Individual, business-related, and work environment factors associated with driving tired among taxi drivers in two metropolitan U.S. cities. J. Saf. Res. 2019, 70, 71-77. [CrossRef] [PubMed] 
16. Baba, M.; Miyama, G.; Sugiyama, D.; Hitosugi, M. Influence of Workplace Environment, Working Conditions and Health Situations of Taxi Drivers on Vehicle Collisions or Near-Miss Incidents. Ind. Health 2019, 57, 530-536. [CrossRef] [PubMed]

17. Japan Ministry of Health, Labor and Welfare. Sleep Guidelines for Health Promotion. 2014. Available online: https://www.mhlw.go.jp/file/06-Seisakujouhou-10900000-Kenkoukyoku/0000047221.pdf (accessed on 6 December 2019).

18. Abe, T.; Komada, Y.; Nishida, Y.; Hayashida, K.; Inoue, Y. Short sleep duration and long spells of driving are associated with the occurrence of Japanese drivers' rear-end collisions and single-car accidents. J. Sleep Res. 2010, 19, 310-316. [CrossRef] [PubMed]

19. Japan Ministry of Land, Infrastructure, Transport and Tourism. Healthcare Manual for Drivers of Commercial Vehicles (Revised Edition, 2016). Available online: http://www.mlit.go.jp/jidosha/anzen/03analysis/resource/ data/h26_2.pdf (accessed on 15 December 2019).

20. Japan Ministry of Land, Infrastructure, Transport and Tourism. Manual for General Guidance and Supervision Provided by Car Operators to Commercial Vehicle Drivers (2) (Revised Edition, 2018). Available online: http://www.mlit.go.jp/jidosha/anzen/03safety/resourse/data/bus_honpen.pdf (accessed on 6 December 2019).

21. Mello, M.T.; Santana, M.G.; Souza, L.M.; Oliveira, P.C.; Ventura, M.L.; Stampi, C.; Tufik, S. Sleep patterns and sleep-related complaints of Brazilian interstate bus drivers. Braz. J. Med. Biol. Res. 2000, 33, 71-77. [CrossRef] [PubMed]

22. Anna, A.; Ihlström, J.; Fors, C.; Kecklund, G.; Filtness, A. Factors associated with self-reported driver sleepiness and incidents in city bus drivers. Ind. Health 2016, 54, 337-346.

23. Diez, J.J.; Vigo, D.E.; Lloret, S.P.; Rigters, S.; Role, N.; Cardinali, D.P.; Chada, D.P. Sleep habits, alertness, cortisol levels, and cardiac autonomic activity in short-distance bus drivers: Differences between morning and afternoon shifts. J. Occup. Environ. Med. 2011, 53, 806-811. [CrossRef] [PubMed]

24. Deza-Becerra, F.; Rey de Castro, J.; Gonzales-Gonzales, C.; León-Jiménez, F.E.; Osada-Liy, J.; Rosales-Mayor, E. Sleep habits, fatigue, and sleepiness in Chiclayo-Peru's bus drivers. Sleep Breath 2017, 21, 745-749. [CrossRef] [PubMed]

25. Chaiard, J.; Deeluea, J.; Suksatit, B.; Songkham, W. Factors associated with sleep quality of Thai intercity bus drivers. Ind. Health 2019, 57, 596-603. [CrossRef] [PubMed]

26. Hitosugi, M.; Gomei, S.; Okubo, T.; Tokudome, S. Sudden illness while driving a vehicle-A retrospective analysis of commercial drivers in Japan. Scand. J. Work Environ. Health 2012, 38, 84-87. [CrossRef] [PubMed]

27. Alvaro, P.K.; Burnett, N.M.; Kennedy, G.A.; Min, W.Y.X.; McMahon, M.; Barnes, M.; Jackson, M.; Howard, M.E. Driver education: Enhancing knowledge of sleep, fatigue and risky behaviour to improve decision making in young drivers. Accid. Anal. Prev. 2018, 112, 77-83. [CrossRef] [PubMed]

28. Japan Ministry of Internal Affairs and Communications. The Current Situation of Chartered-Bus Business (2) 2016. Available online: http://www.soumu.go.jp/main_content/000080871.pdf (accessed on 6 December 2019).

(C) 2020 by the authors. Licensee MDPI, Basel, Switzerland. This article is an open access article distributed under the terms and conditions of the Creative Commons Attribution (CC BY) license (http://creativecommons.org/licenses/by/4.0/). 